\title{
A Study on the English Translation and Introduction of YU Hua's Novels from the Perspective of Medio-Translatology
}

\author{
Tang Yuan \\ School of Humanities and Arts, Jiaxing Nanhu University, Jiaxing, China \\ Email address: \\ ty0732@zjxu.edu.cn

\section{To cite this article:} \\ Tang Yuan. A Study on the English Translation and Introduction of YU Hua's Novels from the Perspective of Medio-Translatology. \\ International Journal of Language and Linguistics. Vol. 9, No. 5, 2021, pp. 269-274. doi: 10.11648/j.ij11.20210905.14
}

Received: October 11, 2021; Accepted: October 27, 2021; Published: October 30, 2021

\begin{abstract}
In the past 20 years, Yu Hua's novels have been systematically translated and introduced to English-speaking countries by Random House, and Yu Hua has also moved from Jiaxing to the world, becoming one of the successful writers in contemporary China. Understanding and analyzing the spread of the English translations of his novels in the English-speaking world is helpful to understand Yu Hua's literary influence in the world. Medio-Translatology is the study of translation in literary communication in comparative literature, which provides a research perspective for the research of the translation of $\mathrm{Yu}$ Hua's works. From the perspective of Medio-Translatology, this paper discusses the translation and dissemination of Yu Hua's novels in the English world by sorting out and analyzing the English versions of Yu Hua's novels, in order to explore the factors for the success of English translation of his works. The research holds that the successful translation and introduction of Yu Hua's novels in the English world mainly lies in the excellent original works. The translator's "creative treason" in the process of translation, the "cultural responsibility" of excellent editors and the works' quality to meet the expectations of the target readers' "evaluation and acceptance" are also the other important factors for the successful translation, introduction and dissemination of works.
\end{abstract}

Keywords: YU Hua's Novels, English Translation, Medio-Translatology

\section{Introduction}

YU Hua is one of the most influential writers in contemporary China as well as a world-renowned writer from Jiaxing, Zhejiang. His works were first translated into English in 1996 and began to spread in English-speaking countries, making YU Hua one of the contemporary Chinese writers who successfully went global. From the perspective of comparative literature, the Medio-Translatology mainly studies the reception methods, communication channels and media of translated works in target language, and their influence on the target literature, which provides a new research horizon for the study of English translation and communication of YU Hua's novels. This paper puts the phenomenon of English translation of YU Hua's novels into the perspective of Medio-Translatology theory. By combing the translation and acceptance history of YU Hua's novels in the English world, combined with the comparative analysis of the translation and the original, the paper discusses the subjective factors such as the translator's "creative treason" in the process of language and culture transformation, the editor's "literary responsibility" in the process of translation spreading in the West, and the evaluation and acceptance of works by Western readers such as sinologists. It can be helpful to understand the social and cultural reasons and dissemination ways of the English versions of YU Hua's novels widely recognized by the English-speaking world, so as to better promote the translation and dissemination of contemporary Chinese literary works in the English-speaking world.

\section{An analysis of the English Translation of YU Hua's Novels and Its Research Status}

The English translation of YU Hua's works was first scattered in the anthology of Chinese avant-garde novels edited by some scholars, such as The Lost Boat: Avant-Garde Fiction from China, 1993 edited by Zhao Yiheng, and Running Wild: New Chinese Writers, 1994 edited by David Der-Wei 
Wang and Jeanne Tai. In 1996, the University of Hawaii Press published the English version of YU Hua's novel collection Past Events and Punishment, which began the process of translating YU Hua's works into English and in the English-speaking world. This work was translated by Andrew Jones, who was only 22 years old at that time, and made YU Hua "the only writer who has published his personal anthology in English at present" in China (p. 256) [1]. In 2003 YU Hua's novel To Live [2], translated by Michael Berry, an associate professor at the University of California, was published by Anchor Books Publishing House under Random House in the United States, which caused great repercussions in the English-speaking world. Many mainstream media such as Washington Post, Time magazine and Seattle Times spoke highly of YU Hua's work, and the English version of To Live also ranked first in the American book list for a long time. In the same year, Andrew Jones's translation of YU Hua's $X u$ Sanguan Selling Blood, which had already been translated into English many years ago, was published in Pantheon Books (2003) and Anchor Books (2004) under Random House after being transferred to several publishing houses [3]. With the continuous translation and publication of his works in the western world, YU Hua's influence in English-speaking countries is growing. From 1996 to now, in the past 20 years, a total of 8 YU Hua's works have been translated into English and published in Random Publishing House. In addition to the three works introduced above, there are other five novels, namely: Cries in the Drizzle: A Novel translated by Allan H. Barr in 2007, published in Anchor Books [4], Brothers translated by Carlos Rojas and his wife Eileen Cheng-yin Chow in Pantheon Books in 2009 [5], and China in Ten Words in 2011 [6], Boy in the Twilight in 2014 [7] and The Seventh Day in 2015 [8], all translated by Allan H. Barr and published in Pantheon Books.

YU Hua is one of the most translated and introduced contemporary Chinese writers in the English-speaking world. Although the English translators of YU Hua's novels are all American scholars, whose fluent and authentic English expressions play an important role in the dissemination of YU Hua's works, there is no systematic study on the publication of English translations of YU Hua's novels in the English-speaking world, and most of the English-speaking world's understanding of YU Hua's works are the comments of mainstream media and translators themselves. At present, domestic scholars' research on English translation of YU Hua's novels mainly focuses on some specific translation strategies and translators' translation views from the perspective of Medio-Translatology and language conversion. For example, Michael Berry's Translation Aesthetics and Cultural Responsibility - Taking the English Translation of "To Live" as an Example (Zhu Zhenwu, 2016) [9], Reproduction and Loss of Repeated Style of "Brothers" in its English Version (Xiong Weiwei, 2014) [10], An Multi-system Interpretation of English Translation of YU Hua's "To Live" (Sun Shanshan, 2016) [11], etc. However, from the diachronic study of the spread of YU Hua's novels in the English-speaking world, there are only few articles published such as An exotic vision: The Translation and Acceptance of "Brothers" in the English-speaking World (Guo Jianling, 2010) [12], Evaluation and Acceptance of the English Version of "Brothers" in the English World (Wang Baorong, 2015) [13], Translation and Dissemination of YU Hua's Works in English-speaking Countries (Li Hanjie, 2014) [14], Research on English Translation and Communication of YU Hua's Works (Zeng Lingling, 2015) [15] and other sporadic papers.

The main content of these papers is a summary of the communication history and translation process of YU Hua's works in the English-speaking world from the perspective of historical data collation, and lacks the deep analysis and research on the English translation of YU Hua's works and the reasons for its recognition in the English-speaking world from the perspective of cultural exchange and influence.

\section{An Analysis of the Dissemination and Acceptance of YU Hua's Novels in the English World}

YU Hua's works are influenced by the profound traditional Chinese culture. His life and work experience in Haiyan, a small town in the south of the Yangtze River, are reflected in his works, which constantly narrates his thoughts, doubts and confusions about the real world and people's destiny. His early reading of western literary works made his novel creation influenced by foreign writers such as Kawabata Yasunari and Kafka very early. Traditional translation studies often pay attention to the comparative analysis between the translated text and the original text, and discuss whether the translated text is "faithful" to the original text in terms of content, style and whether the style of the original text can be reflected. Therefore, in the process of translating and introducing YU Hua's works, it is slightly one-sided to study literary translation and literary relations only from the perspective of language conversion or combing historical materials. So we should study literary translation and literary relations from the perspective of cultural exchange. Medio-Translatology, developed from comparative literature, takes literary translation as its basic research object, not only paying attention to the comparison between the translated version and the original version, but also paying attention to the manipulation of the target culture on literary translation and the relationship between literatures by analyzing the degree of addition and deletion of the translated version, the reasons of distortion and the acceptance of the translated version by the media.

Drawing lessons from the theory of Medio-Translatology, this study focuses on the analysis of the translator's "creative treason", the editor's "literary responsibility", the reader's "evaluation and acceptance" [16] and other factors in the process of translation and introduction of YU Hua's novels, so as to explore the social and cultural reasons and dissemination ways of YU Hua's English versions widely recognized by the English-speaking world, and better promote the translation and dissemination of contemporary Chinese literary works in the English-speaking world. 


\subsection{The Translator's "Creative Treason"}

When Professor Xie Tianzhen examined the concept of "creative treason" in his work Medio-Tanslatology, he pointed out that "if creativity in literary translation shows a subjective effort by the translator to approach and reproduce the original with his own artistic creation, then treason in literary translation is reflected in the translation process, which reflects an objective deviation from the original caused by the translator in order to achieve a certain subjective wish. However, this is only from a theoretical point of view. In practical literary translation, creativity and treason cannot be separated at all, and they are an organic whole. Therefore, Robert Escarpit, a French literary sociologist, put forward a term, 'creative treason', and said, 'Translation is always a kind of creative treason."' (p. 137) [16] As a core concept of Medio-Translatology, in fact, "creative treason" is the symbol of collision, running-in, exclusion and integration between different cultures. It refers to the deviation caused by the translator's inability to return to the author's original intention in the dialogue with the original author due to the domination of pre-understanding such as ideology, poetics and traditional culture, and the understanding, translation and interpretation caused by the deviation of the author's original intention. Like the reader, the translator's understanding is also a kind of re-creation, so some translations are read and accepted by people in a re-creation way that the original author can't imagine. The original must undergo "creative treason" in order to extend its vitality and expand the scope of being read and accepted. Of course, "creative treason" is not equal to all negative "deviations" in a translation, but "the creative behavior completed by the translator driven by a clear re-creation motive, which is a dynamic paraphrasing and transformation of the original work", and its creativity is manifested as "the discovery, demonstration, judgment and recognition of new values". [17]

The English version of YU Hua's To Live was translated by American scholar Michael Berry. After it was published in America, it was a great success. As far as translation subject is concerned, as the only translator, Michael Berry's own cultural concepts, translation competence and other subjective factors directly determine the living conditions of the translated version. By contrastive analysis of the original version and Berry's translation, we can find that there are many deviations between his translation and the original one, which embodies the translator's "creative treason" and becomes the main factor for the translation to be recognized by English readers.

For example, as far as the title of To Live is concerned, generally speaking, the words with the additional word "着" (zhe) in Chinese context indicate the ongoing state, and "To live" can be understood as "living", which is continuing. When used as a title, YU Hua thinks, "To live is a simple phrase, but it contains strong power. The strength to live comes from patience. We should endure the responsibilities life gives us, and endure happiness, sadness, boredom and mediocrity [2]. What To Live wants to convey is an attitude of pursuing life. When Michael Berry translated the title of "to live" into English, he did not translate it into the progressive tense of "living" according to the literal meaning in Chinese, nor did he use the general noun "lifetimes" to translate it into the life of Fu Gui, the hero of the novel. Instead, he creatively chose the infinitive "to live" in English. Michael Berry said that he "once wanted to translate the name of the novel as 'lifetime"'. But in fact, "to live" is more in line with the philosophy conveyed by this novel than "life time", because "to live" means to survive and struggle for survival, and he is not an ongoing state, but an attitude of pursuing life." [18] Although at the linguistic level, Michael Berry's translation is different from the literal meaning of the original text, reflecting the translator's treason, this creative treason just expresses the connotation pursued by the original text. YU Hua believes that people should pay more attention to the process of life. Michael Berry's English title also emphasizes the unusual life in the form of infinitive, which is unique in English, and conveys the attitude of pursuing life. It can be said that it is the translator's carefully crafted and creative English title that attracts the attention of readers in the English world and promotes Living to enter the western world.

\subsection{The Editor's "Literary Responsibility"}

From the perspective of media studies in comparative literature, Medio-Translatology studies translation (especially literary translation) and translated literature. The status of translated literature in national literature and the acceptance of translated works in the target language have always been the focus of Medio-Translatology. In the process of producing a translated text, besides the translator's subjective factors, the reception degree of the translated text in the target language context is influenced by ideology, patronage, cultural tradition and other factors. One of the direct exertors of these factors is the publisher and editor as the patronage of the translated text. W. J. F. Jenner has analyzed the popularity of traditional Chinese novels in the Western target context. It is pointed out that the potential readers and influence of traditional Chinese novels in the West are very limited, and the unpopular factors of translated works include "weak character design", "omniscient narrator", "tendency to reflect sociality rather than individuality", and "taboo challenging established values and world outlook", etc. He believes that to change this situation, editors need to assume "culture duty" [19] so as to promote and promote the exchange and development between different cultures. Zhao Yiheng, editor-in-chief of Lost Ship: Chinese Avant-garde Novels, also criticized the tendency of western editors to "choose and translate Chinese contemporary literature according to the social significance of their works rather than the artistic value". [20]

YU Hua's works are characterized by contemporary avant-garde novels calling for breaking traditions, norms and taboos. In addition, YU Hua has been influenced by western literary tradition since the early stage of his novel creation, and his works are inextricably linked with western literary schools, which just satisfies the editor's intention of showing Chinese "new" literature to the west. Therefore, in the process of editing YU Hua's works, the subjective factors of Western 
editors will inevitably affect the translators and their translation behaviors, and finally affect the spread of the translated works in the Western world.

Take Allen H. Barr, who translated YU Hua's works the most, as an example. Speaking at the Third International Symposium on Literary Translation of Sinologists, "when I first tried to translate Chinese novels more than ten years ago, the reason why I took a fancy to YU Hua's Boy in the Twilight, is that the contemporary Chinese novels that western readers came into contact with at that time often had a strong political flavor, highlighting the differences between Chinese society and western society, while Boy in the Twilight kept a certain distance from Chinese politics, and its content was nothing more than emotional problems, marriage crisis, generation gap and so on that often appeared in daily life. Perhaps for this reason, when the English version of Boy in the Twilight was published in January this year, Random House added a subtitle to the book, Boy in the Twilight: Stories of Hidden China." [21] Not only does the publishing society change the title of the original text, but even the editor will directly let the translator or the original author adapt the work. In Allen H. Barr's view, YU Hua's early works are more elegant, while his later works are more concise in style and simpler in language. He likes YU Hua's writing style, which is very concise and simple, and does not deliberately show his talent. He thinks that this style is also conducive to translation into English, so translators should master the weight and meaning of each word. He said, "Before the English version of Boy in the Twilight was published, some of its novels were published in different journals in the United States, Britain and Hong Kong in the form of single articles, and the editors of these journals sometimes put forward individual amendments. Looking back now, these amendments may be summed up as' Please tell me less'. YU Hua's writing style is very concise, and more than one English editor has suggested deleting what they think is unnecessary." [21] Allen H. Barr also mentioned that the novel editor of the New Yorker suggested deleting the last words of Women's Victory ("She said to Li Hanlin: Let's go home), in order to highlight the changes in the relationship between Lin Hong and Li Hanlin. The editor felt that the previous sentence "Her hand is loosened from Li Hanlin, and her mouth is removed from Li Hanlin's mouth" is already a good ending, so there is no need to add anything more. In this regard, Allen $\mathrm{H}$. Barr believes that "between the lines, the message I get from these editors' amendments is that the author doesn't have to tell the reader so directly, just show it. As long as it is displayed vividly, the reader will naturally understand." [21]

Although these editors start from their own ideology and cultural tradition, The translator or the original author is required to change the work to a certain extent. Objectively, it may deviate from the original work to a certain extent, But it is undeniable that it is the "literary responsibility" that these editors uphold and make YU Hua's translations spread more smoothly in the western world. Anchor Books Publishing House, which publishes the most works of YU Hua in the Western world, belongs to Random House Publishing Company and is the largest book publishing group in the world. It is committed to publishing high-quality contemporary literary works. Its good reputation and strong influence have also made great contributions to the success of English versions of YU Hua's works.

\subsection{The Reader's "Evaluation and Acceptance"}

The successful dissemination of YU Hua's works in the English world is mainly reflected in the readers' acceptance of the English translated works. Medio-Translatology holds that when the translator dedicates the completed translation to the reader, the reader will mobilize his own life experience and join in re-creation in his own way, showing the reader's "creative treason". On the one hand, the reader's "creative treason" comes from his own subjective factors, on the other hand, it also comes from his objective environment-different historical environments will affect the way readers accept works. When faced with works from foreign cultures, Readers in the western cultural environment, starting from their own cultural views, expect to feel new cultural added value in foreign works, meet their needs for foreign cultural experience, and reconcile with their own cultural views to produce new cultural experiences, which will inevitably lead to the collision of cultural concepts. By investigating the readers' comments on YU Hua's works in the western world after translating them into English, and analyzing the acceptance of YU Hua's works by western readers, the researcher can not only analyze the spread of YU Hua's works in the western world, but also provide beneficial enlightenment for Chinese literature to "go global".

In the present intelligent age, online book purchase has largely replaced traditional bookstore sales. Looking at the sales data of the work in the online shop can intuitively explain the acceptance of the work in readers. Amazon North America website is aimed at English-speaking readers, so inquiring the sales data and readers' comments of English versions of YU Hua's works on this website can generally reflect the acceptance and recognition of YU Hua's works in the English-speaking world. The author chooses eight English translations of YU Hua's works, which are being sold on Amazon.com, as the analysis objects. According to the online sales data (as of March 25, 2020), the following table is obtained:

Table 1. Sales Data Sheet of Amazon North America Website for English Translations of YU Hua's Works.

\begin{tabular}{lllll}
\hline Book title & Sales version & $\begin{array}{l}\text { Publication } \\
\text { time }\end{array}$ & $\begin{array}{l}\text { Sales } \\
\text { ranking }\end{array}$ & $\begin{array}{l}\text { Number of readers' } \\
\text { comments }\end{array}$ \\
\hline To Live: A Novel & Kindle & 2007.12 & 16823 & 118 \\
Chronicle of a Blood Merchant & Kindle & 2007.12 & 424192 & 30 \\
Cries in the Drizzle & Kindle & 2008.11 & 1696893 & 10 \\
Brothers: A Novel & Kindle & 2009.1 & 312868 & 49 \\
\hline
\end{tabular}




\begin{tabular}{|c|c|c|c|c|c|}
\hline Book title & Sales version & $\begin{array}{l}\text { Publication } \\
\text { time }\end{array}$ & $\begin{array}{l}\text { Sales } \\
\text { ranking }\end{array}$ & $\begin{array}{l}\text { Number of readers' } \\
\text { comments }\end{array}$ & Average score \\
\hline China in Ten Words & Audible & 2012.8 & 51519 & 154 & 4.6 \\
\hline Boy in the Twilight: Stories of the Hidden China & Kindle & 2014.12 & 1839484 & 36 & 3.3 \\
\hline The Seventh Day: A Novel & Kindle & 2015.1 & 309298 & 46 & 4.2 \\
\hline The April $3^{\mathrm{Rd}}$ Incident: Stories & Kindle & 2018.11 & 1352683 & 0 & 0 \\
\hline
\end{tabular}

From Table 1, we can find that the English versions of YU Hua's two most famous masterpieces, To Live and Brothers, have higher sales volume, readers' comments and evaluation scores than his other works in the English world. Judging from the total number of translated works published in the United States every year, the sales of English versions of YU Hua's works are also relatively high. Compared with the online sales data of English versions of Mo Yan's works, which won the Nobel Prize for Literature, Mo Yan's English version of Red Sorghum ranks 249,271, with 77 readers' comments and 3.6 readers' comments. The English version of his Big Breasts and Fat Buttocks ranks 160086, with 54 readers' comments and 3.1 comments. The sales data of YU Hua's English version of To Live is much better, which reflects that YU Hua's works have been accepted and recognized by Western English readers to a certain extent. In addition, among the three indicators of sales volume, number of comments and scores of this data table, the English version of China in Ten Words by YU Hua ranks first. In this book, the author tells several short stories around ten common words: "people, leaders, reading, writing, Lu Xun, gap, revolution, grassroots, cottage and fudge", and truthfully records his feelings about the development of contemporary China. The title and content of the book cater to the psychology of western readers who are eager to understand the reality of China and find clues to understand the development of Chinese society from the book.

Let's take a look at online English readers' comments on the English version of YU Hua's works. For example, reader chichi8980 commented on YU Hua's novel Living:

"Great works! I don't like reading novels, especially when I have to read a novel every three days for class. But I suddenly like reading Alive, and I forget to eat and sleep to read this book. The whole book describes the sufferings of this life everywhere, but it has the satirical taste of comedy, which is really wonderful! "1

Reader Brainingirlon commented on YU Hua's novel Brothers:

"This book was published as two novels when it was published. The first, set in the context of the Cultural Revolution, is the most exciting, amazing, and arguably the most perfect work since Anna Karenina. Every character described in the book is so vivid that you are eager to experience it with them, whether it is a good thing or a bad thing. Don't miss every chapter in the book. This book is really wonderful! "2

Judging from these readers' comments on the English versions of YU Hua's works on the website, most of them are praise words, which also reflects that YU Hua's works have been recognized and accepted by readers in the English world.

\footnotetext{
${ }^{1}$ https://www.amazon.com/s?k=Yu+Hua\&ref=nb_sb_ss_fb_1_20. 2020-03-25.

2 See also: https://www.amazon.com $/ \mathrm{s}$ ? $\mathrm{k}=\mathrm{Yu}+\mathrm{Hua} \& \mathrm{ref}=\mathrm{nb}$ _sb_ss_fb_1_20. 2020-03-25.
}

Through YU Hua's works, English readers have a deeper understanding of China and Chinese culture, which also arouses their interest in further reading Chinese writers' works and promotes Chinese contemporary literature to the world.

\section{Conclusion}

Over the past 20 years, YU Hua's works have been translated into English by Western translators according to their interests, and published by Random House, the largest publisher in the world. YU Hua's works have spread rapidly in the English-speaking world, and YU Hua has also become one of the representatives of Chinese contemporary writers successfully going to the world. Combing the translation and introduction of YU Hua's works in the English world from the perspective of Medio-Translatology, we can find that the translator's "creative treason", the editor's "cultural responsibility" and the reader's "evaluation and acceptance" play a great role in the process, which may provide beneficial enlightenment for Chinese contemporary literary works to go global. Besides the important condition that the original is an excellent work, the translator's competence, excellent editorial team and readers' expectation in the target language are also the main factors for successful translation and introduction of a literary work.

\section{References}

[1] Kinpley, J. C. (2000). A bibliographic survey of publications on Chinese literature in translation from 1949 to 1999 . in D. Wang (ed.). Chinese literature in the Second Half of a Modern Century. Bloominton \& Indianapolis: Indiana Uni Press.

[2] Yu, H. (2003). To Live. Trans. by Michael Berry. New York: Anchor Books Publishing House.

[3] Yu, H. (2003). Xu Sanguan Selling Blood. Trans. by Andrew Jones. New York: Pantheon Books.

[4] Yu, H. (2007). Cries in the Drizzle: A Novel. Trans. by Allan H. Barr. New York: Anchor Books Publishing House.

[5] Yu, H. (2009). Brothers: A Novel. Trans. by Carlos Rojas \& Eileen Cheng-yin Chow. New York: Pantheon Books.

[6] Yu, H. (2011). China in Ten Words. Trans. by Allan H. Barr. New York: Pantheon Books.

[7] Yu, H. (2014). Boy in the Twilight. Trans. by Allan H. Barr. New York: Pantheon Books.

[8] Yu, H. (2015). The Seventh Day. Trans. by Allan H. Barr. New York: Pantheon Books.

[9] Zhu, Zhenwu \& YANG Leipeng. (2016). Michael Berry's Translation Aesthetics and Culture Responsibilities. Journal of Sichuan International Studies University, 32 (3), 89-94. 
[10] Xiong Wei-wei. (2014). Recreation and Loss of Repetitions in the English Version of "Brothers"From the Perspective of Rhetorical and Musical Effect. Journal of Harbin University, 35 (6), 96-99.

[11] Sun, Shanshan. (2016). A Poly-system Study on the English Translation of Yu Hua's "Huozhe". Central China Normal University.

[12] Guo, Jianling. (2010). An exotic vision: The Translation and Acceptance of "Brothers" in the English-speaking World. Contention in Literature and Art, 23, 65-70.

[13] Wang, Baorong. (2015). Evaluation and Acceptance of the English Version of "Brothers" in the English World. Journal of Sichuan International Studies University, 31 (4), 65-71.

[14] Li, Hanjie. (2014). Translation and Dissemination of YU Hua's Works in English-speaking Countries. Journal of Liaoning Institute of Technology (Social Science Edition), (5), 61-63.

[15] Zeng, Lingling. (2015). Research on English Translation and Communication of YU Hua's Works. Journal of Zhejiang International Studies University, (4), 60-64, 69.

[16] Xie, Tianzhen. (2007). Introduction to Medio-Translatoloy. Beijing: Peking University Press.
[17] Sun, Jianlu. (2001). On creative treason of translation in comparative literature research. Journal of Theory. (4), 118-120.

[18] Han, Siyu. (2014). A comparative study of the English versions of Living from the perspective of translator-centered theory. Journal of Shanxi Agricultural University, (12), 1270-1274.

[19] Jenner, W. J. F. (1990). Insuperable barriers? Some thoughts on the reception of Chinese writing in English translation. In H. Goldblatt (ed.). World Apart: Recent Chinese Writing and its Audiences. New York: M. E. Sharpe. 177-97.

[20] Zhao, Y. H. (1993). The new waves in recent Chinese fiction. In Y. H. Zhao (ed.). The Lost Boat: Avant-Garde Fiction from China. London: Wellsweep Press.

[21] Allen, H. Barr. (2014). On Cultural Differences in Literary Acceptance and Translation Strategies. http://www.chinawriter.com.cn/2014/2014-08-26/215845. 2014-08-26.

\section{Biography}

Tang Yuan (1980-), master, lecturer, School of Humanities and Arts, Jiaxing Nanhu University. Her research interests: literary translation. 